\title{
Usability in the Product Design Process Based on the Intelligent Microprocessor
}

\author{
Ke Su $(\mathbb{D})$ and Hao Ma $(\mathbb{D}$ \\ College of Art and Design, Qilu Industry University, Jinan, 250353 Shandong, China \\ Correspondence should be addressed to Ke Su; coco_su0716@163.com and Hao Ma; 1043119103@stu.qlu.edu.cn
}

Received 28 September 2021; Revised 23 October 2021; Accepted 28 October 2021; Published 13 November 2021

Academic Editor: Haibin Lv

Copyright (C) $2021 \mathrm{Ke} \mathrm{Su}$ and Hao Ma. This is an open access article distributed under the Creative Commons Attribution License, which permits unrestricted use, distribution, and reproduction in any medium, provided the original work is properly cited.

\begin{abstract}
The sharing and reuse of product design experience knowledge is beneficial to shorten the product development cycle and improve product quality. The intelligent microprocessor has greatly changed the way of interaction between people and computers. This article mainly studies the usability analysis in the product design process based on the intelligent microprocessor. The experiment must first perform initial finite element calculations, and the purpose is to complete the data collection. The collection of evaluation indicators is carried out with the help of perceptual vocabulary classification, and the hierarchical inference method is used to build a tree-like analysis chart. After the indicator collection is completed, the Likert scale method is used to screen the indicators, and the evaluators will rate the selected indicators according to their importance. The Petri net modeling method is used to model the product design process, which mainly includes task element definition, task module division, task planning, and task allocation. Finally, the usability test of the product is carried out. Experimental data shows that the probability of completing the design task within 30 days is $27.74 \%$. The results show that the intelligent microprocessor shortens the time-consuming process of product design and at the same time enhances product usability.
\end{abstract}

\section{Introduction}

The transformation of social economy, the increasingly intensified market competition, and the diversified development of science and technology have made consumers' demands and expectations increasingly expand, and the positioning and role of products have also changed. In our country, the research and application of product usability and user experience are rising rapidly, arousing widespread interest in the research field, and also major well-known enterprises and emerging technological innovation enterprises have also increased their investment in usability engineering. Therefore, studying UCD methodology in the product development life cycle is of great significance to both theory and practice.

In this paper, the intelligent microprocessor is applied to the field of product design evaluation, which expands and complements the methods of product design evaluation, provides new ideas for the development direction of product design evaluation under the background of science and technology and information, and provides a new platform for the communication among users, designers, engineers, and evaluators. At the same time, it provides an effective basis for the simulation verification of new products before they are put into the market. Through the quantitative processing of subjective design evaluation, it can better grasp the needs of consumers and control the design direction, which is of great significance to improve the success rate and efficiency of design.

Product design is a very complex process. Xia believes that product design and manufacturing simulation is a promising research and application field of tactile. Through natural human-computer interaction and realistic torque feedback, tactile can change the traditional design and manufacturing methods. He has conducted a detailed and comprehensive survey of the haptics used in product design and manufacturing simulation over the past 10 years, including tactile for product design and shape modeling, for machining simulation, and for virtual assembly and maintenance simulation. He introduced new tactile devices and rendering algorithms and discussed the main research work and typical systems. His research content is too limited 
[1]. The NURBS surface is the same as the NURBS curve in the shape project column, which forms the final shape to be created through the combination of multiple surfaces. There are two types of adjustment points on NURBS curves and surfaces: points edit points and CV control points. Pernot et al. believe that the use of free shapes has become the mainstream for designing complex products that must meet engineering requirements and aesthetic standards. Even though the CAD system can easily express free shapes through NURBS surfaces, its definition and modification still require deep knowledge and superb skills in operating the basic mathematical model. The implementation of free-form designers is time-consuming and cannot be quickly modified. In order to overcome these limitations, they have carried out some research to try to adapt to the characteristic concepts successfully used for regular shape design in the field of free concepts. They described and compared various methods. Their research lacks innovation [2]. Du et al. provide an overview of the latest technology on LFJO problems based on the typical decision chain of engineering optimization, including successive stages of problem formation, optimization modeling, model solution, and optimization evaluation. They also reviewed the current status of twolevel programming (BLP) models for LFJO problems, focusing on their engineering implications for PDD. They also reviewed popular algorithms used to solve BLP mathematical models, as well as common practices for LFJO model evaluation in the PDD literature. Finally, they discussed the key issues of the LFJO problem and the prospects for further research. The factors considered in his research are not comprehensive [3]. For example, there is insufficient research on the development conditions, development costs, and maintenance costs of the technology. Tiwari et al. believe that design concept evaluation is one of the most important stages in the early stages of the design process because it not only affects the later stages of the design process but also affects the success of the final design solution. Their main purpose is to reduce inaccurate content in the customer evaluation process, thereby improving the effectiveness and objectivity of product design. They proposed a novel method for performing design concept evaluation. This method does not need to consider the cost and benefit characteristics of design standards but instead determines the best concept that can meet the constraints imposed by the designer team on the design standards and meet the preferences of the largest customer. In this work, they developed an improved VIKOR method for rough numbers by modifying the extended VIKOR method by using interval numbers for design concept evaluation. Their research lacks necessary experimental data [4]. The VIKOR decisionmaking method they mentioned is a compromise ranking method, which compromises and ranks limited decisionmaking schemes by maximizing group utility and minimizing individual regret values. The VIKOR method is an effective tool for multicriteria decision-making (MCDM). It is used in the following situations: (1) the decision-maker cannot or does not know how to accurately express his preferences; (2) there are conflicts and incommensurability between evaluation criteria (different measurement units); and (3) decision-makers dealing with conflict issues can accept compromise solutions.

This paper applies the intelligent microprocessor to product design evaluation and builds a model framework of the product design evaluation system that applies the intelligent microprocessor. At the same time, the sharing technology of product design knowledge can effectively integrate the existing design resources and design results, share the design process through the network, accelerate the product design speed, and shorten the product development design cycle. This paper takes users as the center, evaluates the usability of the product design process and design quality, tries to apply it to different types of products and different design processes, and finally forms the usability evaluation standard of product design, which is the evaluation of design results, and also the user participation in the design process solves the problem of too subjective design evaluation.

\section{Intelligent Microprocessor in Product Design}

2.1. Intelligent Microprocessor. The intelligent microprocessor in product design has changed the previous twodimensional or three-dimensional rendering design, which digitizes the three-dimensional model, accurately and intuitively, and can provide a real design object so that consumers or designers can experience products, evaluate products, and validate products on the same platform. They can be in or in front of the evaluation object and evaluate the scale, space, structure, proportion, color, and texture through simulation $[5,6]$.

Since the introduction of microprocessors, microprocessors have been quickly introduced into various industries and have completely changed the design ideas of products. For example, common smart products such as computers, scientific calculators, tablets, smart phones, smart watches, and smart switches all use smart microprocessors. Take a smart phone as an example. The processor is the core component of the mobile phone. It is the control center system of the entire mobile phone and the control core of the logic part. The microprocessor achieves the purpose of overall monitoring of the mobile phone by running the software in the memory and calling the database in the memory. With the continuous improvement of the integrated circuit production technology and process level, the functions of the microprocessor in the mobile phone are becoming more and more powerful, such as the integration of advanced digital signal processors in the microprocessor. The performance of the processor determines the performance of the entire phone. Through the digital conversion of analog signals, information can be stored conveniently, measured values can be analyzed in real time, and various syntheses and processing can be performed. And this pushes product design to a new era of computerization and intelligence. The intelligent microprocessor makes the product scheme from two-dimensional drawings and three-dimensional models and imitates the product's shape, color, material, size, and other attributes, providing a virtual viewing and using the digital product for evaluation and verification by 


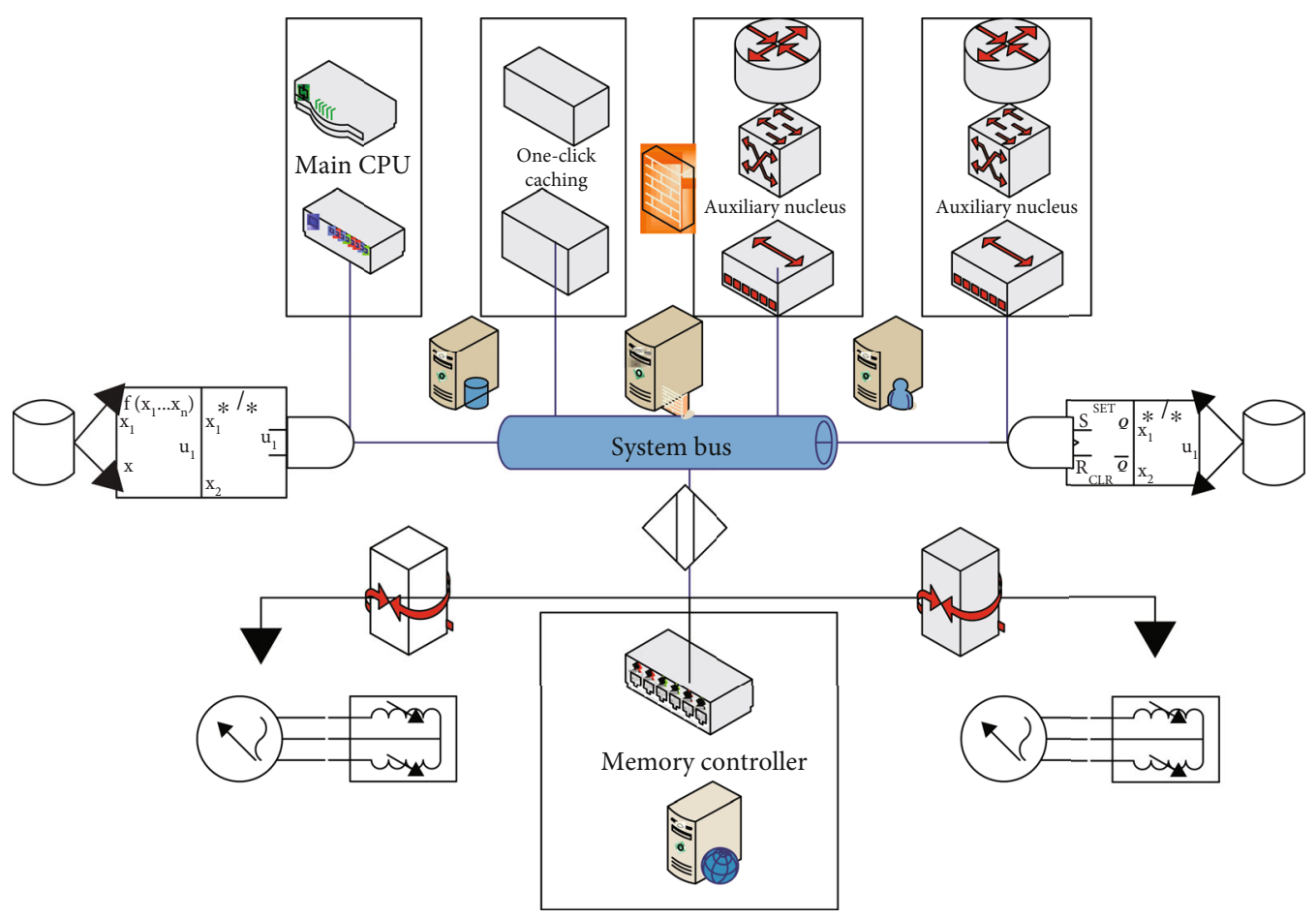

Figure 1: Structure of the heterogeneous SMP processor.

evaluators. The intelligent microprocessor can simulate the appearance of the product in all directions and with high precision. The intelligent microprocessor first accepts processing instructions, which must be executed in strict accordance with the order specified by the program to ensure the correctness of the computer system. Secondly, the corresponding operation control signals are sent to the corresponding components so as to control these components to perform corresponding operations according to the requirements of the instructions. During the operation of the instruction, strictly follow the time specified in the instruction. After all program operations are completed, perform arithmetic and logical operations on the data or perform other information processing. After all data processing is completed, the entire product can be simulated. In addition, the intelligent microprocessor can also build a product use environment to simulate the use process of the product. Through strong technical support, the evaluators can observe and use the products in a realistic natural and reasonable use environment and make the evaluation results more reasonable [7]. The specific processor chip structure is shown in Figure 1.

It can be seen from Figure 1 that more and more heterogeneous multicores have appeared in recent years. Heterogeneous multicore hardware is different in architecture. The CPU is mainly responsible for executing serial tasks and logic control. GPU has great advantages in parallel computing due to its thread-level parallelism. CPU and GPU heterogeneous multicores can give full play to the performance advantages of CPU and GPU in their respective application scenarios. The principle is to integrate cores of different sizes into the same chip according to specific needs-application computing requirements. At the same time, the multithreaded microprocessor structure provides multiple hardware sites, that is, the program execution context environment, so that the CPU can run in accordance with multiple control threads at the same time, and each execution site saves the running state of a currently running thread, including general register files and the program counter. These hardware sites save the thread state of the same address space on site and can execute lightweight threads. The model is shown in Figure 2.

As shown in Figure 2, from an architectural point of view, simultaneous multithreaded processor technology implements multiple relatively independent logical processors on a physical processor core. Each logical processor has its own architecture description. During operation, each logical processor can independently suspend, interrupt, and directly execute a specific thread without being affected by the state of another logical processor. At the same time, due to the use of the largest hardware support, the thread switching efficiency is relatively high.

The entity and virtual body are inseparable. The dialectical relationship between them constitutes products and determines the grade of products. On the one hand, the two are interrelated. The virtual body belongs to ideology. It cannot exist in isolation but must rely on the entity. In other words, in the process of design, we must consider whether the materials, design tools, and related processing equipment can support the completion of the product manufacturing. Moreover, the perceptual elements of products need to be externalized with the help of product entities [8]. In addition, human beings live in the real environment, which is full of objective entities. The objective entities are 


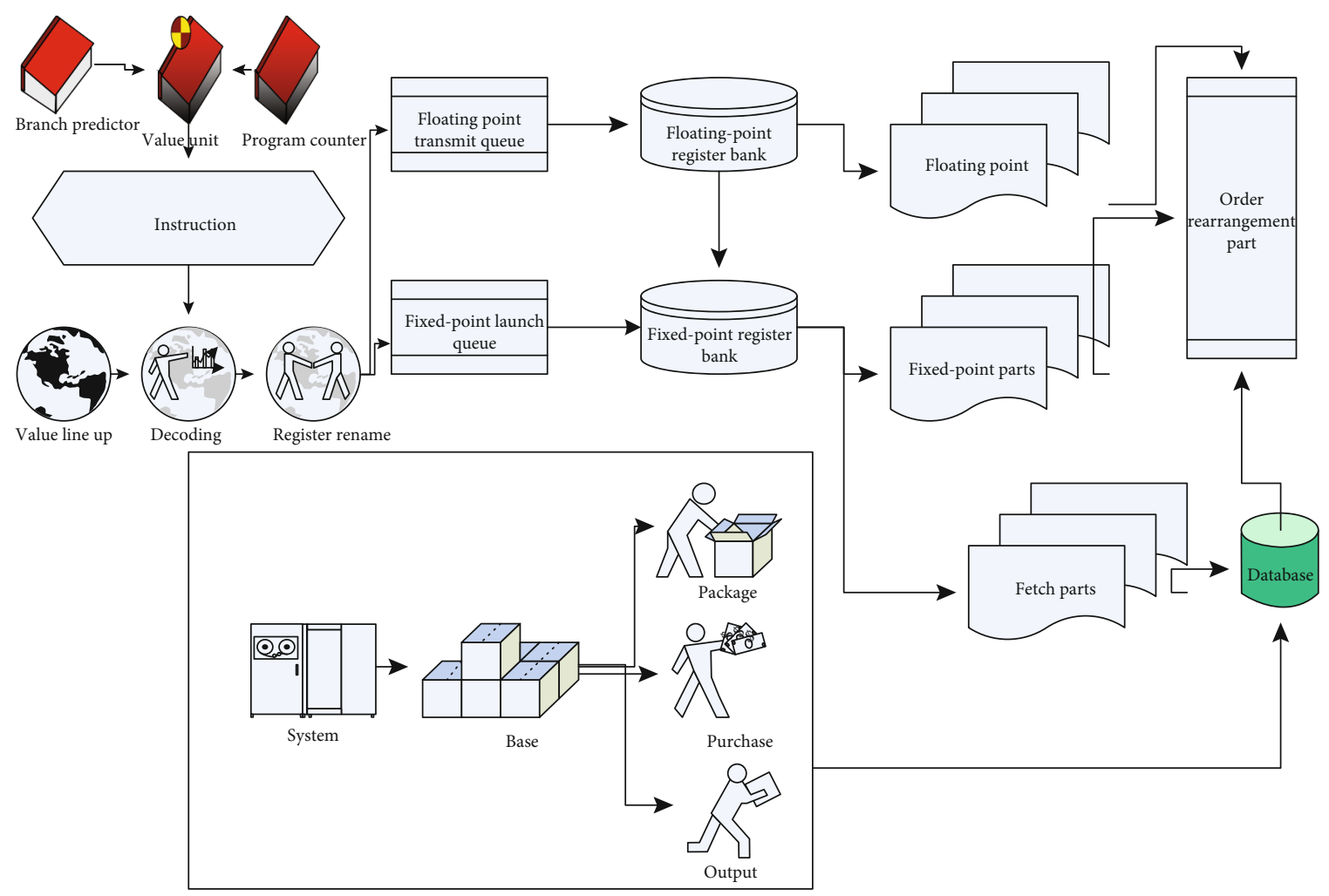

FIGURE 2: Simultaneous multithreading microprocessor model.

the necessities of human life, and the real sense of human existence also needs to be reflected by product entities [9]. On the other hand, the two restrict each other. The perfection of the entity elements directly restricts the embodiment of the virtual elements. Without the support of the entity, no matter how unique the creativity is, no better idea can be realized, and then the excellent products cannot be used by people. At the same time, virtual elements have initiative, and appropriate virtual elements will promote the development of physical elements and then create high-level products [10]. On the contrary, it will produce low-grade products. Therefore, in the process of product design, the construction of virtual elements is to give product emotion and then use reasonable methods to pass the emotional state of the product to consumers, thus affecting the evaluation of product formation by consumers. The construction process of emotional experience is to automatically store the consumer's experience and feelings about a certain product in memory, and then the short-term memory is strengthened to form some unconscious tendency or prejudice, which will unconsciously affect consumers' cognition of a certain product $[11,12]$.

The virtual design principle is shown in Figure 3. In the virtual design environment, the digital model of mechanical products is used to build a computable digital prototype. On this basis, it simulates the physical prototype in the real world for operation and analysis. A virtual prototype is an integrated design of computer-supported mechanical product modeling, simulation, and product description, simulating all necessary product data and manufacturing processes.
The interaction between the design world and the virtual world includes the virtual design environment, which integrates mechanical product definition, design engineering, and manufacturing $[13,14]$.

2.2. Product Design. The product platform is of great significance for the future development of enterprises. When planning the product platform, on the one hand, it is necessary to meet the individual needs of market segments and customers. On the other hand, it is necessary to develop an appropriate product platform according to the situation of the product itself and the operation status of the enterprise to ensure the low cost and high efficiency of design and production. Therefore, when enterprises adopt a platform strategy for product design, they should first determine the type of product platform that conforms to their own situation and has stability [15]. The design task module division process is shown in Figure 4. The product design project obtains the final task element through the task decomposition and the related task element adjustment rule, carries on the correlation analysis to the task element, establishes the comprehensive correlation matrix between the task elements, lays the foundation for the subsequent module division, then uses the method of the clustering analysis and genetic optimization algorithm to divide the task element module, and realizes the process solution through MATLAB. Finally, the optimal module partition scheme under the given conditions is obtained [16].

On the basis of module partition, for the parallel execution module, the Petri net model under parallel relation can be 


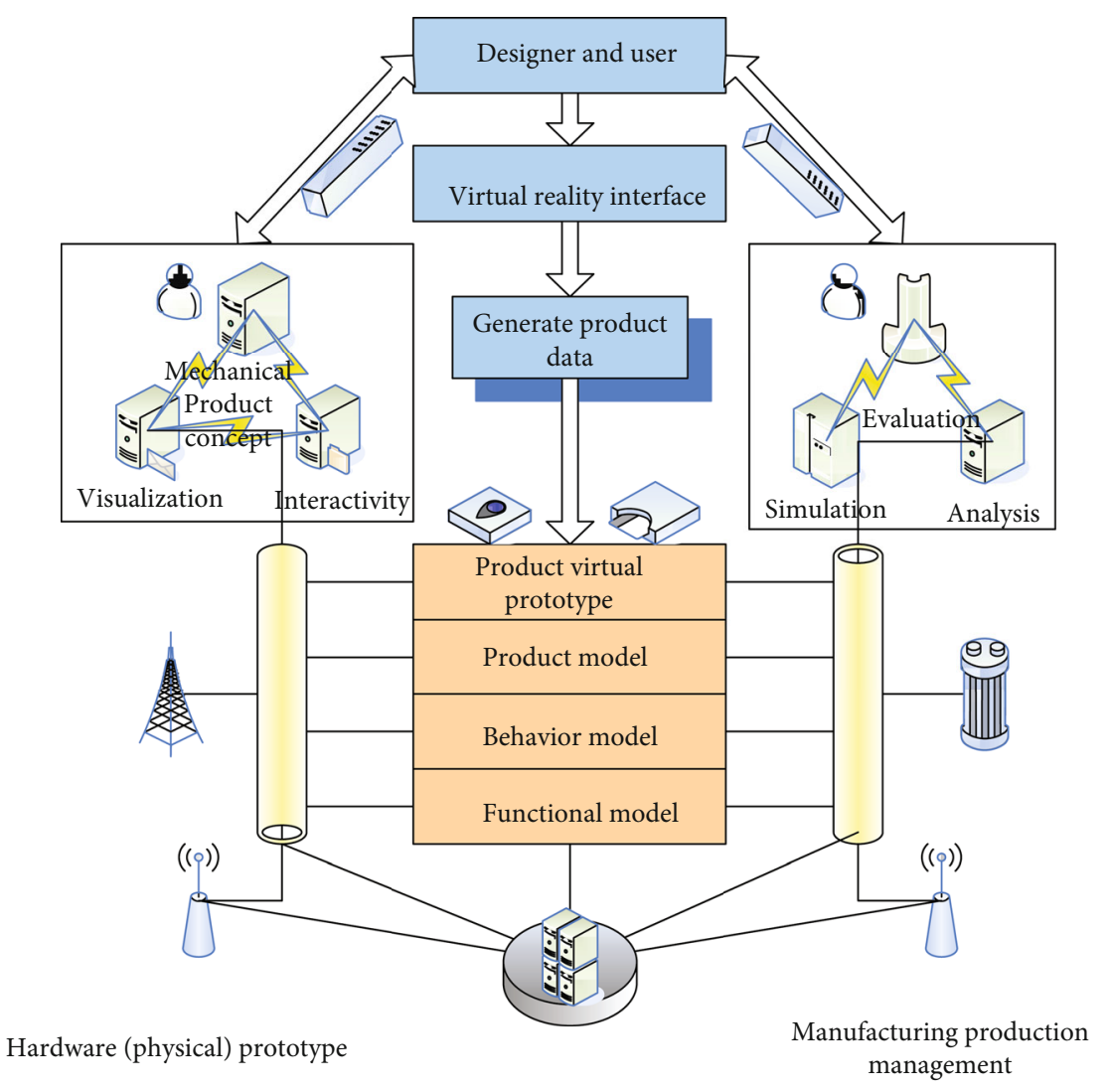

FIgURE 3: Virtual design principle.

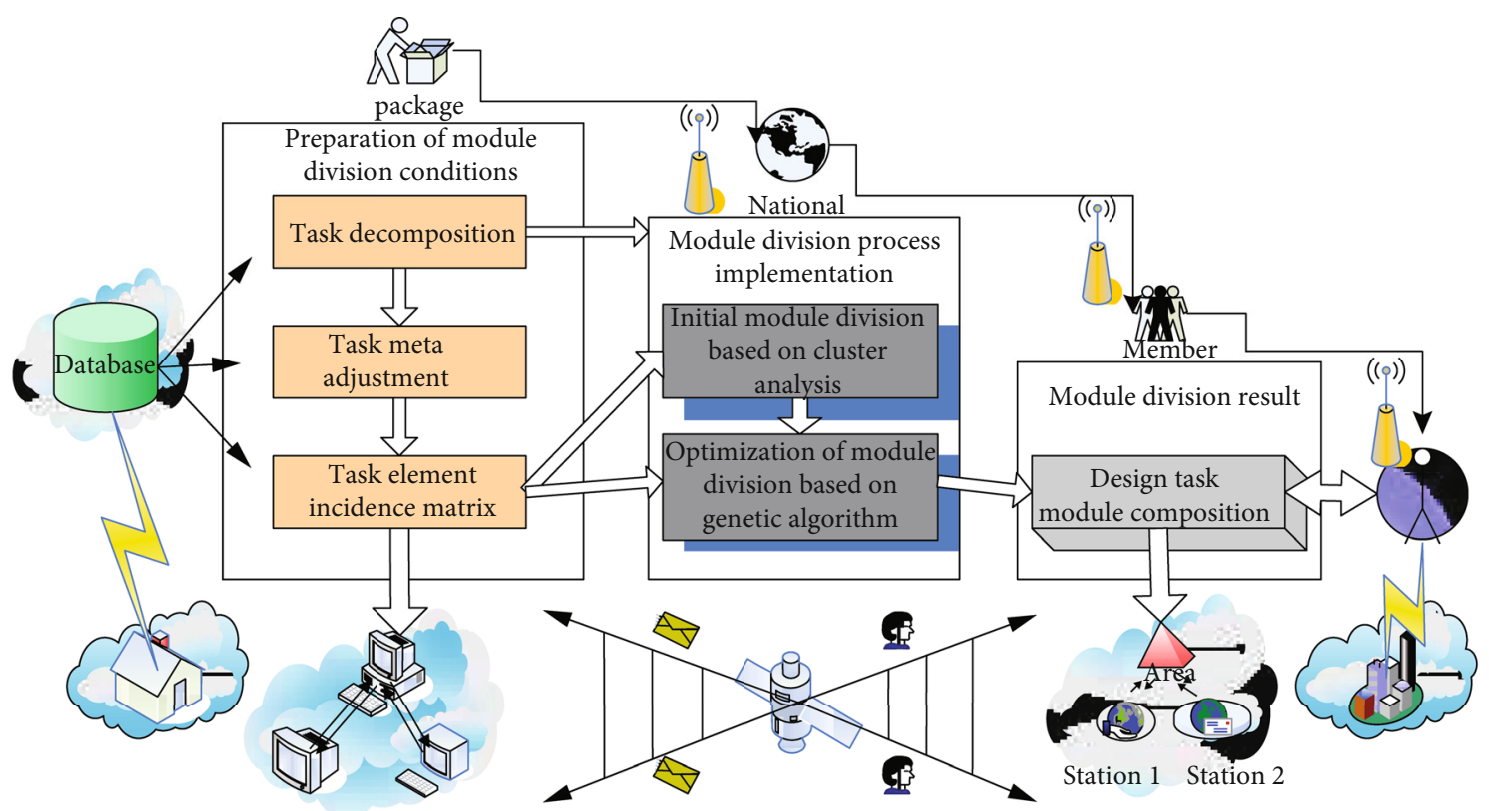

FIgURE 4: Design task module division.

directly selected. It can express the dynamic and sequential requirements of the process, support the dynamic simulation of a product system, have a strict formalization mechanism, have precise semantics and a strict mathematical basis to verify the correctness of the process model, support process con- currency, solve the synchronous competition problem of the advanced Petri net, and improve the modeling and analysis function of the Petri net from different angles [17].

Assuming that the $i$-th task element belongs to the $k$-th module, set $x_{i k}=1$; otherwise, set $x_{i k}=0$. Define the task 
meta-aggregation index in the $k$-th module as follows:

$$
\mathrm{MI}_{k}=\frac{\sum_{i=1}^{n-1} \sum_{j=i+1}^{n}\left(r_{i j} \cdot x_{i k} \cdot x_{j k}\right) / r_{\max }}{\sum_{i=1}^{n-1} \sum_{j=i+1}^{n} r_{\max } \cdot x_{i k} \cdot x_{j k}},
$$

where $r_{\max }$ is the maximum value of $r_{i j}$ in the incidence matrix, $n$ is the number of task elements, and $k$ is the number of modules. Then, all the aggregation degrees of the entire product are as follows:

$$
M_{0}=\frac{\sum_{p=1}^{k}\left[\sum_{i=1}^{n-1} \sum_{j=i+1}^{n} r_{i j} \cdot x_{i k} \cdot x_{j k} \cdot \mathrm{MI}_{k}\right]}{\sum_{k=1}^{k}\left(\sum_{i=1}^{n-1} \sum_{j=i+1}^{n} r_{\max } \cdot x_{i k} \cdot x_{j k}\right)}
$$

Define the coupling index between module $\alpha$ and module $\beta$ as follows:

$$
\mathrm{MO}_{\alpha \beta}=\frac{\sum_{i=1}^{n} \sum_{j=1}^{n}\left(r_{i j} \cdot x_{i \alpha} \cdot x_{j \beta}\right) / r_{\max }}{\sum_{i=1}^{n} \sum_{j=1}^{n} r_{\max } \cdot x_{i \alpha} \cdot x_{j \beta}} .
$$
lows:

The coupling degree between product modules is as fol-

$$
M_{S}=\frac{\sum_{\alpha=1}^{k-1} \sum_{\beta=\alpha+1}^{k}\left[\sum_{i=1}^{n} \sum_{j=1}^{n} r_{i j} \cdot x_{i \alpha} \cdot x_{j \beta} \cdot \mathrm{MO}_{\alpha \beta}\right]}{\sum_{\alpha=1}^{k-1} \sum_{\beta=\alpha+1}^{k}\left(\sum_{i=1}^{n} \sum_{j=1}^{n} r_{\max } \cdot x_{i \alpha} \cdot x_{j \beta}\right)}
$$

The calculation process of the data interface complexity is as follows:

$$
H_{a}=-\frac{1}{k} \sum_{j=1}^{k}\left(\frac{\sum_{q=1}^{n_{a j}} a_{j q}}{\sum_{i=1}^{n} a_{i}}\right) \ln \left(\frac{\sum_{q=1}^{n_{a j}} a_{j q}}{\sum_{i=1}^{n} a_{i}}\right) .
$$

In the formula, $n_{a j}$ represents the number of task elements constituting the $j$-th module.

The calculation engineering of cost complexity is as follows:

$$
H_{c}=-\frac{1}{k} \sum_{i=1}^{n}\left[c_{r i} \cdot \ln c_{r i}+\left(1-c_{r i}\right) \ln \left(1-c_{r i}\right)\right] .
$$

In the formula, $c_{r i}$ represents the relative cost of the entity corresponding to the $i$-th $(i=1,2, \cdots, n)$ design task.

The expression for normalization is as follows:

$$
X=\frac{X-X_{\min }}{X_{\max }-X_{\min }}
$$

The fitness function is constructed as follows:

$$
\text { Fitness }=\left\{\begin{array}{l}
\frac{1}{c+F} \\
\frac{1}{c+F+T}
\end{array}\right.
$$

where $F$ is the objective function and $c$ is the conservative estimate of the objective function, which is a nonnegative number.

Compared with the knowledge process, the product design process is much more complicated, and it is necessary to define and maintain the relevant information of all design activities. At the same time, the definition of the product design process mainly relies on the definition of the product structure, while taking into account the dynamics of the design process, managing and coordinating user execution, and dynamically controlling the human, resource, and time factors of the design process [18].

According to the rough set theory, assuming that $R=\{$ $\left.C_{1}, C_{2}, \cdots, C_{n}\right\}$ is the evaluation result set of $n$ persons, then

$$
\begin{gathered}
\underline{\operatorname{Apr}_{C_{i}}}=\cup\left\{C_{k} \leq C_{i}\right\}, \quad k=1,2, \cdots, n, \\
\overline{\operatorname{Apr}_{C_{i}}}=\cup\left\{C_{k} \geq C_{i}\right\}, \quad k=1,2, \cdots, n .
\end{gathered}
$$

The fuzzy number of $C_{i}$ is as follows:

$$
\begin{gathered}
\mathrm{RN}_{C_{i}}=\left[C_{i}^{\mathrm{L}}, C_{i}^{\mathrm{U}}\right], \\
C_{i}^{\mathrm{L}}=\frac{\sum \frac{\operatorname{Apr}_{C_{i}}}{M_{\mathrm{L}}}}{C_{i}^{\mathrm{U}}}=\frac{\sum \overline{\operatorname{Apr}_{C_{i}}}}{M_{\mathrm{U}}} .
\end{gathered}
$$

Among them, $M_{\mathrm{L}}$ represents the number of the lower limit of $C_{i}$, and $M_{\mathrm{U}}$ represents the number of the upper limit of $C_{i}$. The evaluation set $R$ is transformed into a fuzzy number:

$$
\begin{gathered}
\mathrm{RN}_{R}=\left[R^{\mathrm{L}}, R^{\mathrm{U}}\right], \\
R^{\mathrm{L}}=\frac{1}{n} \sum_{i=1}^{n} C_{i}^{\mathrm{L}}, \\
R^{\mathrm{U}}=\frac{1}{n} \sum_{i=1}^{n} C_{i}^{\mathrm{U}} .
\end{gathered}
$$

Design evaluation refers to the method of comparing and selecting schemes and clarifying the design value and advantages and disadvantages of each scheme in the product design process so as to screen out the best scheme. According to the above algorithm model, the scores in the design scheme scoring table can be converted into evaluation coefficients. The conversion formula is as follows:

$$
o_{11}=\sum_{u=1}^{5} l_{1}\left(w_{u k}\right) o_{u}=l_{1}\left(w_{11}\right) o_{1}+l_{1}\left(w_{12}\right) o_{2}+l_{1}\left(w_{13}\right) o_{3} \text {. }
$$

Among them, $o_{11}$ is the evaluation coefficient of the first row of the gray evaluation sample matrix $W$ in evaluating the gray category "excellent"; according to the above 
method, the evaluation coefficient of each evaluation index and the total evaluation coefficient can be calculated. The proportion of the evaluation coefficient of a certain evaluation index belonging to each gray class in the total evaluation coefficient is called the gray class weight coefficient.

$$
\begin{gathered}
e_{u k}=\frac{o_{u k}}{o_{k}}+o_{1}+\sum_{u=1}^{n} o_{u k}, \\
e_{1}=\left[\begin{array}{ccc}
0.22 & 0.49 & 0.1 \\
0.4 & 0.43 & 0.1 \\
0.33 & 0.41 & 0.16 \\
0.51 & 0.16 & 0.24 \\
0.4 & 0.43 & 0.08 \\
0.41 & 0.49 & 0.01
\end{array}\right], \\
e_{2}=\left[\begin{array}{lll}
0.32 & 0.53 & 0.06 \\
0.03 & 0.47 & 0.47 \\
0.01 & 0.42 & 0.12 \\
0.31 & 0.54 & 0.07 \\
0.23 & 0.54 & 0.15 \\
0.21 & 0.52 & 0.18
\end{array}\right] .
\end{gathered}
$$

Setting the indicators "excellent" and "good" as the output indicators of the evaluation system and the indicator "poor" as the input indicators of the system, the following forms of the DEA evaluation model can be established:

$$
\min c=v^{s} b_{n p} t . s\left\{\begin{array}{l}
m^{s} a_{n}-v^{s} b_{n} \geq 0, \\
m^{s} a_{n 0}=1, \\
v \geq 0 ; m \geq 0 .
\end{array} \quad n=0,1,2, \cdots, o\right.
$$

Among them, $a_{n 0}$ and $b_{n 0}$ are the input and output vectors of the $n$-th evaluation index of the product being evaluated, the following is a model evaluation of the above two product design schemes, and the quality cost evaluation of design scheme 1 is selected as an example, and the evaluation equation is expressed as follows:

$$
\min c_{11}=0.25 v_{1}+0.51 v_{2}, \quad m_{1} \geq 0, v_{1} \geq 0, v_{2} \geq 0 .
$$

This paragraph extends the usability research to the stage of design evaluation and usability testing, extracts the different needs of users, producers, and designers, and analyzes usability evaluation methods.

2.3. Usability Research. Usability is an inherent attribute of the product. When the product is determined, the usability of the product will be determined like its other attributes. That is to say, the usability of a product is completely determined by the product design. Under normal circumstances, two products with the same function do not mean that they are equally easy to use. This is the difference in the usability design of different products, so product usability determines the competitiveness of products. Usability analysis indicators are data sources and related information that we use to measure the level of product usability and discover usability problems [19]. The topic of knowledge points should use the concepts in the domain ontology as much as possible to ensure that knowledge points can be created and managed according to the semantic relationship between domain ontology concepts. Domain ontology is a common method for enterprises to express the semantic relationship between common professional terms and professional terms. In the knowledge distribution service system, the domain ontology needs to be constructed first as the basic data for creating knowledge points and acquiring knowledge [20].

Usability research is user-centered and has practical significance in various industries. Some industries and all service industries are based on customers. In the knowledge service system, knowledge points can be used to represent all kinds of product-aided design knowledge, such as the design method, design principle, design experience, design rules, fact knowledge, product model, process knowledge, and design example, and then stored in the knowledge base in the form of knowledge points. With the global allocation of resources and the developed and convenient sales network, the price war is becoming more and more difficult [21]. In order to maintain a huge production machine, the quality is getting lower and lower. In order to attract customers, businesses are not only constantly reducing prices but also belittling the image of products. Consumers cannot get high-quality products. Price competition is important for enterprises, but it is not a long-term strategy. Large enterprises invest more money to seek breakthrough points to meet consumer demand through usability research, and small- and medium-sized enterprises also make new attempts on individual products [22]. Some basic characteristics of a product system with good usability are shown in Figure 5 .

It can be seen from Figure 5 that, to sum up, products with good usability mainly perform well in the " $5 \mathrm{E}$ " dimensions.

\section{Model Simulation Experiment of the Product Design Process}

3.1. Experimental Environment. The authenticity of the VR system is closely related to two factors: the corresponding time delay of the system and the number of polygons used to construct the graphics. The delay time is less than $10 \mathrm{~ms}$; its authenticity is stronger; the longer the delay, the longer the user's waiting time, the worse the authenticity. It is an important task of the software to generate a realistic view. Constructing polygons into visual graphics is the most commonly used method [23].

3.2. Data Collection. The data obtained in the CAD process can be used to check the calculation results and functions synchronously, and the knowledge obtained from this can 


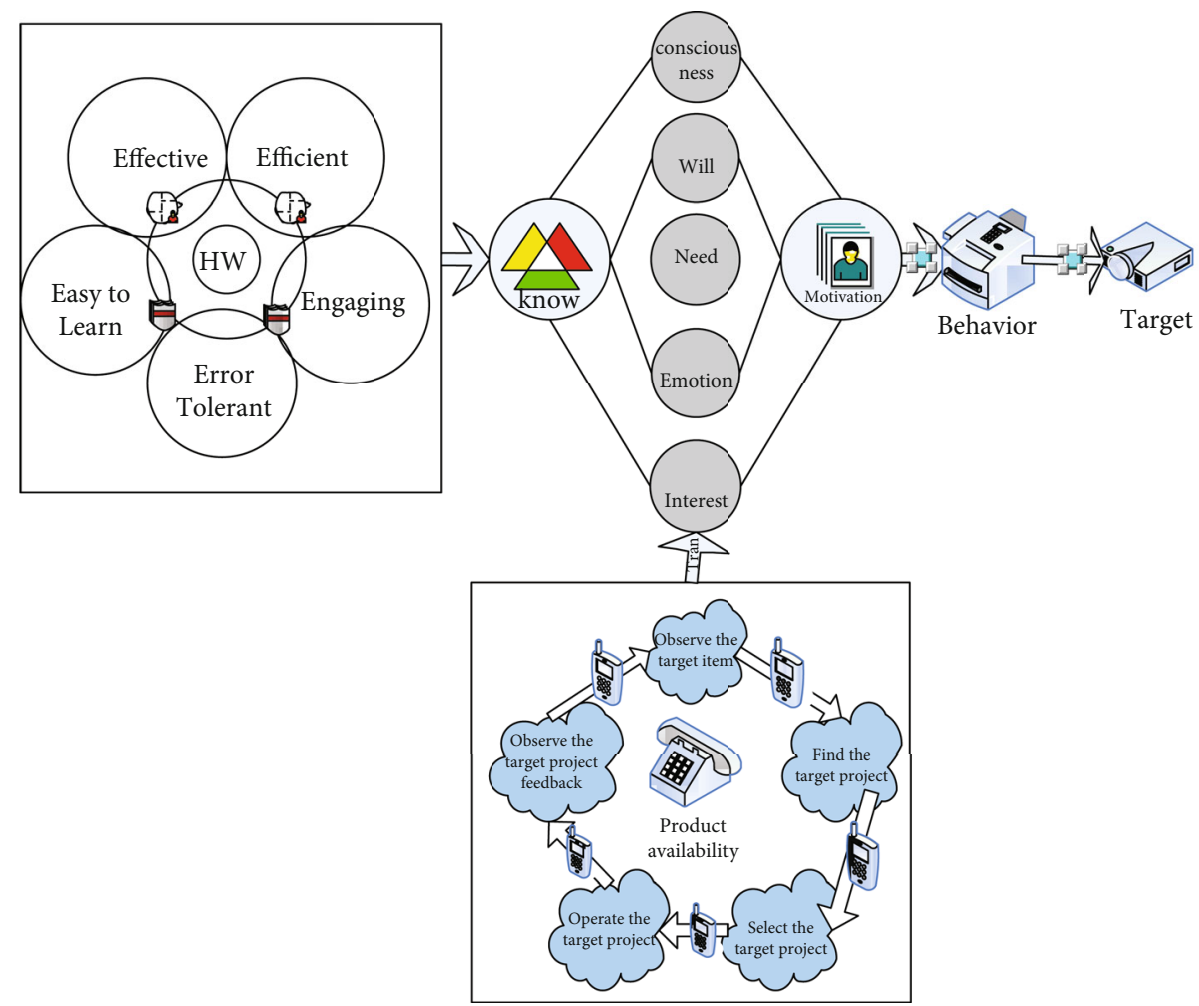

FIgURE 5: The "5 Es" of product availability.
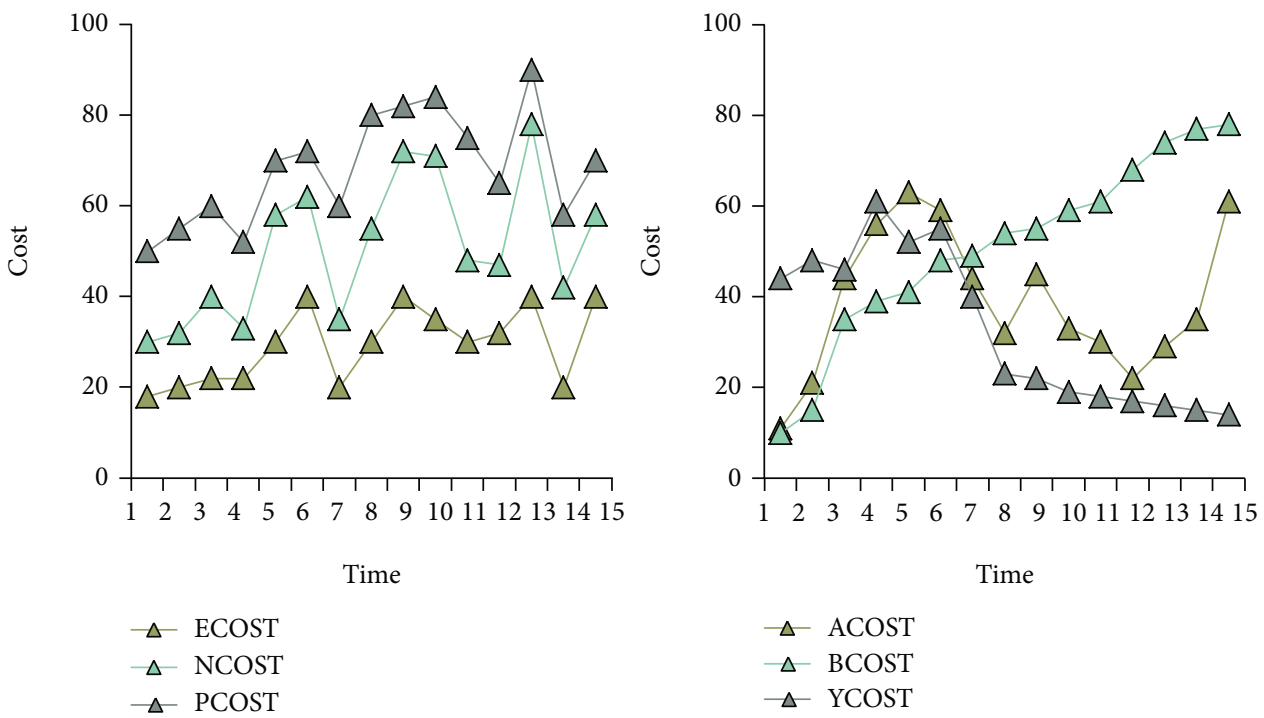

FIgURE 6: The changing law of process cost.

be fed back to the design process. The complete geometric description of the product can be used for initial finite element calculations. The intelligent microprocessor can test and evaluate the product and track and collect the evaluation data of the operator through related equipment. The data composed of data obtained through testing and evaluation has changed the complicated and cumbersome methods of traditional prototype testing and market testing and is in line with the testing requirements of developed products [24].
3.3. Establishment of the Evaluation System. After the evaluation object is determined, the evaluation indicators are collected, and the evaluation indicators are screened and classified by reasonable methods, and the evaluation index model is constructed [25].

(1) The evaluation indicators are collected and expanded with the help of the perceptual vocabulary classification method, and the tree analysis chart is established by the hierarchical inference method, 
TABLE 1: Standardized task time.

\begin{tabular}{lccccc}
\hline Time & Average task time & Standard deviation & Maximum acceptable time & $Z$ value & $Z$ value normalization \\
\hline Task 1 & 13 & 4.82 & 7 & -1.24 & $10.75 \%$ \\
Task 2 & 26.75 & 2.86 & 30 & 0.44 & $67 \%$ \\
Task 3 & 2.19 & 0.28 & 2.5 & 1.11 & $86.7 \%$ \\
Task 4 & 14.03 & 1.61 & 13.93 & -0.06 & $47 \%$ \\
Task 5 & 9.83 & 1.64 & 9.5 & -0.20 & $42 \%$ \\
\hline
\end{tabular}

TABLE 2: Summary of behavior indicator data.

\begin{tabular}{ccccccc}
\hline Participant ID & Cuboid & Pyramid & Cylinder & Cone & Sphere \\
\hline \multirow{5}{*}{ Number 1 } & A & 10 & 12 & 8 & 7 & 5 \\
& B & 2 & 1 & 0 & 0 & 0 \\
& C & 0 & 1 & 0 & 0 & 0 \\
& D & 11 & 11 & 9 & 9 & 7 \\
& A & 9 & 11 & 8 & 8 & 6 \\
Number 2 & B & 1 & 0 & 1 & 0 & 0 \\
& C & 0 & 1 & 0 & 0 & 0 \\
& D & 11 & 10 & 8 & 8 & 6 \\
& A & 10 & 13 & 9 & 6 & 5 \\
Number 3 & B & 0 & 2 & 0 & 0 & 0 \\
& C & 0 & 1 & 0 & 0 & 0 \\
& D & 9 & 12 & 9 & 6 & 6 \\
\hline \multirow{5}{*}{ Non }
\end{tabular}

TABle 3: Number of fixations in the three layouts.

\begin{tabular}{lcccccccccccc}
\hline Numbering & 1 & 2 & 3 & 4 & 5 & 6 & 7 & 8 & 9 & 10 & 11 & 12 \\
\hline Layout 1 & 41 & 21 & 52 & 48 & 70 & 35 & 28 & 32 & 44 & 32 & 49 & 27 \\
Layout 2 & 51 & 27 & 90 & 90 & 76 & 19 & 20 & 20 & 26 & 32 & 64 & 38 \\
Layout 3 & 49 & 22 & 91 & 66 & 81 & 16 & 23 & 18 & 27 & 42 & 67 & 42 \\
\hline
\end{tabular}

and the details are obtained gradually. Through the evaluation, personnel experience the product use environment, and it carries on the full discussion and obtains the analysis chart

(2) After the completion of index collection, it is necessary to simplify and screen the collected indicators, exclude unnecessary indicators, classify and sort out the indicators, and establish the evaluation index model. 40 evaluators scored the importance of the collected perceptual indicators by using the Likert scale. For each index, the evaluators choose a grade to express the attitude of the index as the importance of product evaluation [26]

(3) A quantitative statistical method is adopted to calculate the weight of indicators. The importance of $N$ selected evaluation indicators is investigated and divided into five grades: unimportant, less important, important, more important, and very important

3.4. Product Design Process Modeling. The workflow of the product design process is modeled by the Petri net modeling method. For the large complex product design process, workflow modeling needs to complete the following work: task element definition, task module division, task planning, and task allocation [27].

(1) Design Preparation Process. After the task arrives, the task module is formed through the preparation process, and the process is modeled by the Petri net.

(2) Execution Process between Modules. According to the planning results, the task modules are independent of each other, so they are executed in parallel.

(3) Task Element Preparation Process. Before opening the design process, the decomposed task element needs some design information input.

(4) Block Execution. The module execution process is the process of concreting the task elements in each module, and it is the subprocess of module design.

3.5. Usability Testing. Usability testing is a process of evaluating the usability level. It can evaluate the efficiency and effectiveness of users in achieving tasks. It is a standardized method so that every aspect of each application can satisfy user-friendliness, functionality, and artistry.

(1) One-to-One User Test. In the user experiment operation, we understand the user's operation and thinking, and professional evaluators come to discover the problem data in detail.

(2) Heuristic Evaluation. Users find problems based on usability principles, and users prioritize the problems [28].

3.6. Data Processing. The design parameters of product design evaluation in the intelligent microprocessor are taken as the input of the network, and the result of product design evaluation is the output of the network, and the hidden layer is in the middle. The product evaluation data and results obtained in the network environment are used as network training samples for model training. After training, click the evaluation to obtain the relevant evaluation data value [29].

\section{Usability Analysis of the Product Design Process}

4.1. Impact of the Intelligent Microprocessor on Product Design. Through iteration, the product design scheme becomes more and more specific, but at the same time, it also increases the difficulty of defining the logical relationship between activities, which makes the design cycle and design cost difficult to estimate, and brings great pressure to the optimization and management of the product design process. A reasonable iterative model is the basis of effective 

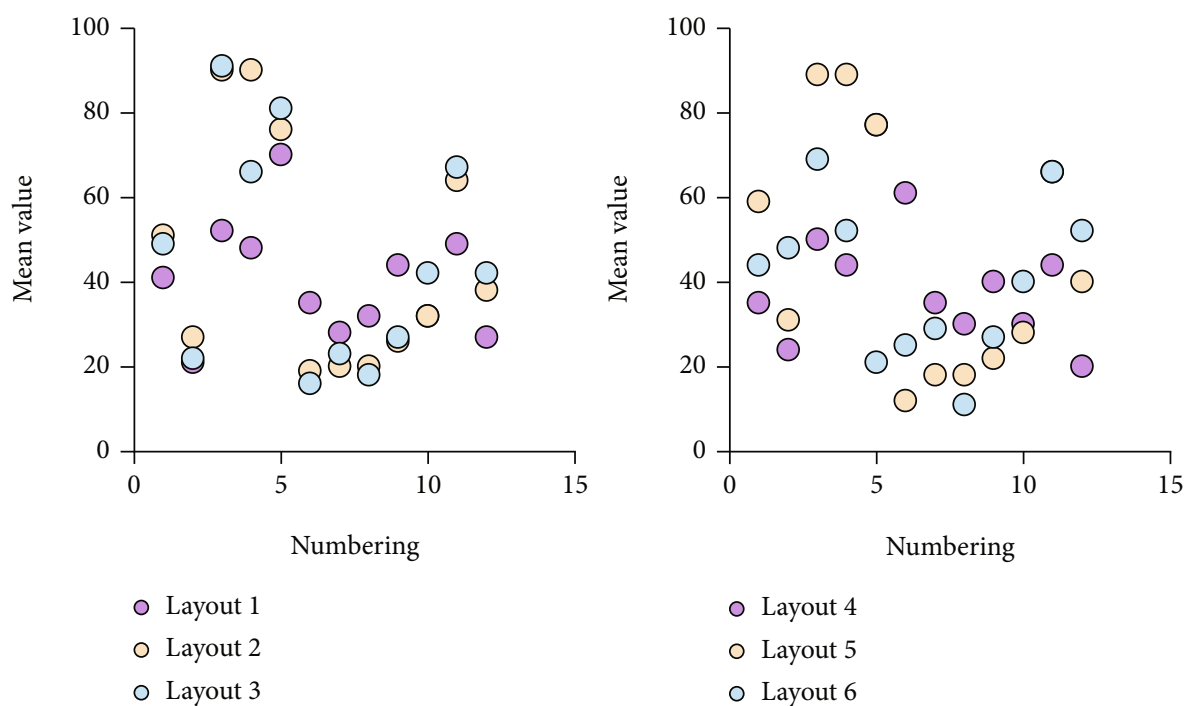

Figure 7: Number of fixations in three layouts.

TABle 4: Model simulation results.

\begin{tabular}{lccc}
\hline $\begin{array}{l}\text { Number of } \\
\text { trials }\end{array}$ & $\begin{array}{c}\text { Number of } \\
\text { conditions met }\end{array}$ & $\begin{array}{c}\text { Cumulative } \\
\text { times }\end{array}$ & $\begin{array}{c}\text { Likelihood } \\
\text { value }\end{array}$ \\
\hline 5000 & 1389 & 1389 & 0.2778 \\
10000 & 1384 & 2773 & 0.2773 \\
15000 & 1381 & 4154 & 0.2769 \\
20000 & 1392 & 5546 & 0.2773 \\
25000 & 1386 & 6932 & 0.2773 \\
30000 & 1390 & 8322 & 0.2774 \\
35000 & 1391 & 9713 & 0.2775 \\
40000 & 1395 & 11108 & 0.2777 \\
\hline
\end{tabular}

simulation and analysis of the design process. The change rule of process cost is shown in Figure 6. The expected process cost is the same as the unfinished expected process cost at the beginning of the process. Generally speaking, the expected cost of the unfinished process will decrease while the actual cost will gradually increase with the progress of the process. The sum of the two is the expected process cost at a certain time. The expected cost of the process should be used when optimizing the process before it starts. The expected cost of the uncompleted process should be considered the optimization objective when the process is optimized. It can be seen from the figure that the change modes of the three costs are similar, and the change of the expected process value is affected by the parameters such as the learning coefficient and information evolution coefficient, especially when the learning coefficient and information evolution coefficient are small, and the influence is more obvious.

The foundation of the realization of natural interaction is the support of technology. In the traditional interaction, due to the single form of interaction, the realization of technology relies more on traditional computer technology, such as image display and instruction processing. However, in a natural interaction scene, because the behavior becomes richer and the senses are more diversified, the natural interaction scene is often supported by a variety of technologies, such as sensor technology for capturing user behavior, neural network technology for intelligent understanding and processing of user behavior, and machine learning for deep learning of the scene. The standardized task time is shown in Table 1. According to the results in the table, the operation time of task 1 is relatively long, and that of task 2 and task 3 is relatively short.

Product display design is not only timely but also interactive. Behavior data index analysis is to analyze the user behavior index data obtained in the process of in-depth observation of the subjects so as to have a more accurate understanding of the behavior rules and habits of the subjects in the modeling process with objective data. The summary of behavior index data is shown in Table 2. Through the data in the table, we can find that the tested subjects tend to be consistent in the overall data; that is, each subject tends to be consistent in the modeling process of the same geometry, and there is no significant difference change. Therefore, it shows that the subjects have similar cognition and operation habits to the modeling task under the guidance of the interactive behavior of modeling software, which is consistent with the actual situation in the observation. Therefore, there is almost no difference in cognition and understanding in the traditional modeling software based on GUI. Users can quickly master the interaction mode after corresponding training.

4.2. User Needs in the Product Design Process. The number of fixation points under the three layouts is shown in Table 3 and Figure 7 . The number of fixation points in layout 1 was significantly lower than that in layout 2 and layout 3, which was due to the fact that layout 1 could provide information more clearly and more in line with the subjects' cognition and was more effective in the process of observing the three interfaces in order to obtain task information. 


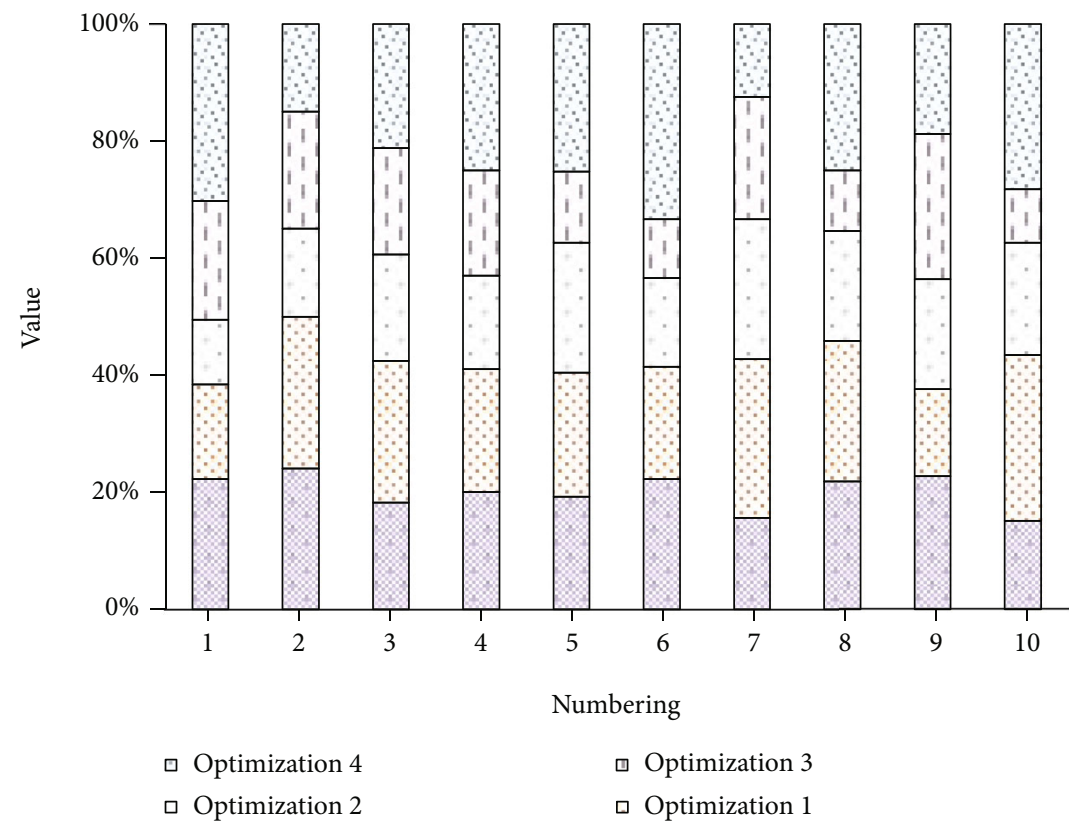

FIGURE 8: Statistics of the number and probability of completing design tasks within 30 days before and after optimization.

TABLE 5: Comparison results of characteristics.

\begin{tabular}{lcccc}
\hline Group & $\begin{array}{c}\text { Number of } \\
\text { observations }\end{array}$ & Sum & Mean & Variance \\
\hline $\begin{array}{l}\text { Horizontal } \\
\text { layout }\end{array}$ & 12 & 74625 & 6218.75 & 24335.48 \\
Vertical layout & 12 & 78960 & 6580 & 82093.27 \\
Central layout & 11 & 69854 & 6574 & 62478.21 \\
Edge layout & 10 & 66857 & 6614 & 52142.32 \\
\hline
\end{tabular}

However, layout 2 and layout 3 are not clear enough, and the subjects' line of sight needs to turn back repeatedly, which leads to the increase of fixation points and the decrease of information acquisition efficiency, which affects the usability of the interactive interface. According to the fixation paths of the three subjects, it can be seen that the fixation sequence path of layout 1 is clearer and simpler than that of layout 2 and layout 3, with fewer detours and lower fixation points. At the same time, according to the experimental task setting, the three subjects were able to search information according to the established logic, and they were relatively fuzzy and uncertain in layouts 2 and 3. According to the comprehensive evaluation model of intelligent product interaction interface usability, layout 1 has lower design complexity, higher interaction efficiency, better user cognition, and better usability.

The simulation results of the model are shown in Table 4. From the result of simulation analysis, the possibility of the design process to complete the task within 30 days is still relatively low, and the distribution range of task completion time is large. Some measures should be taken to improve the design process within the specified cost range so as to improve the design quality and shorten the product development time. With the increase of simulation times, the simulation accuracy is higher and more stable. The probability of completing the design task in 30 days is $27.74 \%$.

Under the condition of given task quantity, the corresponding resource demand will also change if the time constraint is changed. In the same way, the optimal allocation of resources can be obtained by changing the proportion of resources to affect the completion time and resource utilization efficiency of the design process. The statistics of times and probability of completing design tasks within 30 days before and after optimization are shown in Figure 8. The single optimization effect of optimization scheme 1 and optimization scheme 2 is better than that of optimization scheme 3, and the optimization effect of three optimization schemes can be superimposed; after optimization scheme 4 is formed by three optimization schemes, the possibility of completing design tasks in 30 days for building product equipment detailed design process instance is increased to $69.73 \%$, without a significant increase in design cost. Within the specified design time, the task completion rate is increased by $42 \%$, and the optimization effect is remarkable.

4.3. Process Planning Results. Although the product principle structure model is an expression of the actual structure of the product in principle, it also corresponds to a certain function. It can express its corresponding different working states through graph theory. The working state of the product principle structure model can be expressed by the category of energy, and the corresponding energy conversion matrix and other transformations are used to determine the working state corresponding to the product principle structure model, and then we use the representation method in graph theory to perform different working states. Expression provides an object basis for optimizing redundant components. For the product principle structure model, different principle components may correspond to the process of 


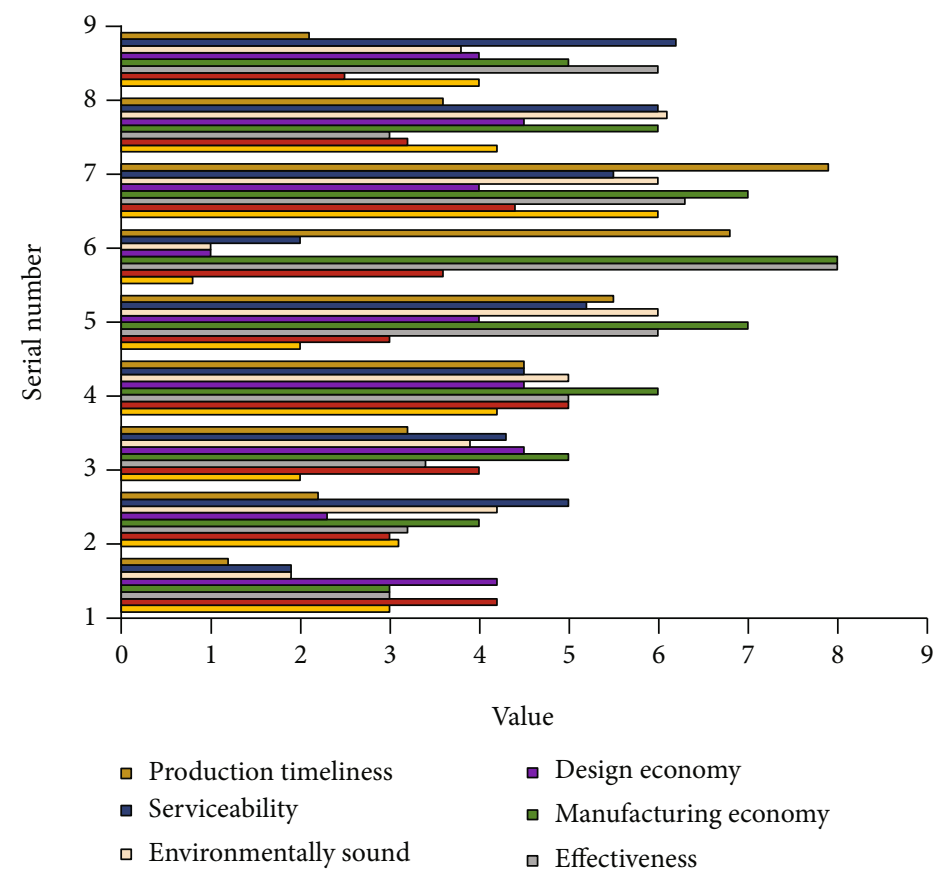

FIGURE 9: Extraction of design quality features of the vibrating screen.

TABLE 6: Experimental results of semantic similarity calculation.

\begin{tabular}{lcccccc}
\hline Threshold $\theta$ & & 0.3 & 0.4 & 0.5 & 0.6 & 0.7 \\
\hline \multirow{2}{*}{ Sample 1 } & Precision & 0.79 & 0.74 & 0.88 & 0.81 & 0.77 \\
& Recall rate & 0.92 & 0.90 & 0.81 & 0.69 & 0.66 \\
\multirow{2}{*}{ Sample 2 } & Precision & 0.53 & 0.55 & 0.60 & 0.46 & 0.41 \\
& Recall rate & 0.66 & 0.66 & 0.58 & 0.57 & 0.52 \\
\hline
\end{tabular}

energy generation, consumption, storage, and conversion, and they can be combined to realize the effect on energy. In order to ensure that the system corresponding to the product principle structure model has input energy and output energy and to prevent the continuous circulation of energy, it is stipulated that there is no structural loop in the product principle structure model, and energy can be output through the system.

The comparison results of the advantages and disadvantages of the features are shown in Table 5. The purpose of metadata is to clearly describe and present the information of the design object. In the construction of the metadata framework in the field of data science, in order to ensure the consistency and integrity of various standards, metadata is usually divided into three levels. In the field of design, three-tier data decomposition can clearly express the information of the design object. At the same time, it is easy to ensure that the metadata information does not deviate from the information subject of the design object. The probability between groups is $p=0.000899<0.05$, and the horizontal and vertical layout has a significant impact on the task completion efficiency. According to the current informatization level of small- and medium-sized enterprises, the data of design quality information is still mainly based on ordinary document data, so most of the quality information will be stored and managed in an unstructured way in the PDM system. Some data information that is convenient for structured management should be managed in a structured way through data decomposition as much as possible.

The design quality feature extraction of the vibrating screen is shown in Figure 9. According to the user requirements for the design quality of the vibrating screen, the design quality characteristic information of the vibrating screen are accurately extracted based on the technology of the house of quality, including the design quality characteristic elements and their relative importance, which are as follows: plastic arts (0.036); system reliability (0.064); efficacy and practicability (0.494); structural manufacturability (0.136); manufacturing economy (0.023); design economy (0.075); environmental harmlessness (0.127); maintenance convenience (0.030); and production time (0.020). Modern product design methods based on the intelligent microprocessor still pay attention to the expression of product form semantics. At the same time, the performance of the product form in the network environment is different from the performance in the real environment. In the network environment, user experience and testing are carried out through computers, so it is necessary to highlight the morphological characteristics of products and highlight the characteristics of product design.

4.4. Model Analysis of the Product Design Process. In the serial process, all the design is completed and handed over to the process, the process is fed back, and the problematic part is redesigned. Although there is process feedback before the design is all qualified, there is only design iteration, so it is a serial process. In addition to the parallel and iterative characteristics of product parallel design, it also has 


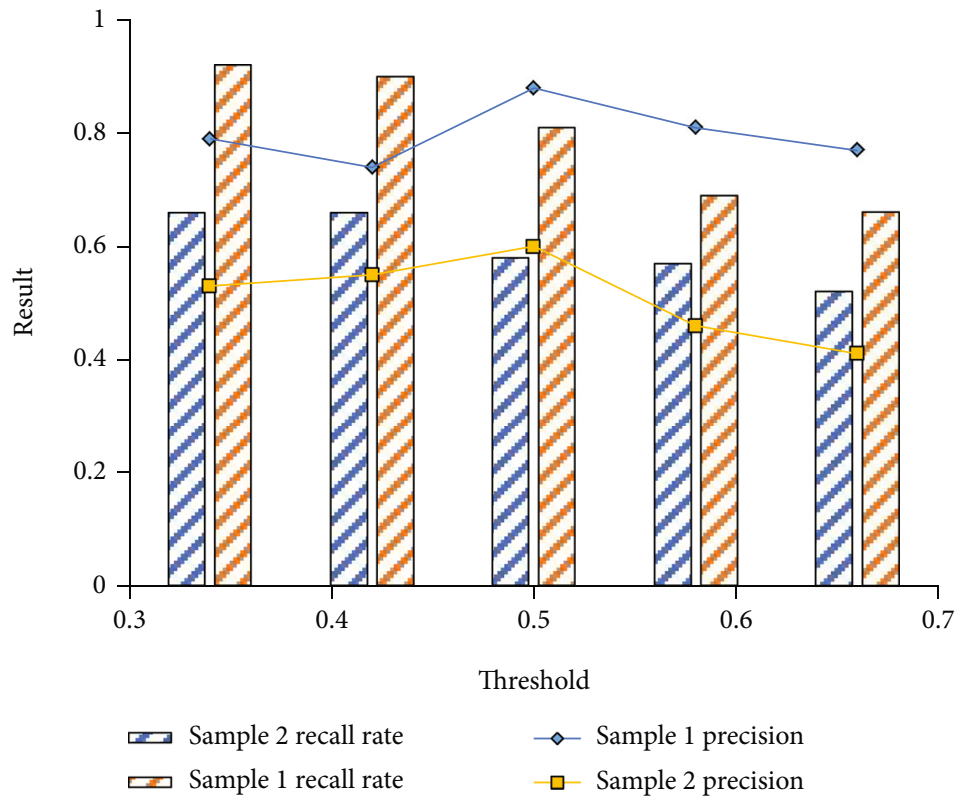

FIGURE 10: Experimental results of semantic similarity calculation.

overlapping characteristics. It is manifested in the process of upstream product design information from vague to clear during the specific design and process implementation, while the downstream process design progresses to a certain level in the upstream product design. The stage begins instead of after the design is over.

According to the different distribution of concepts, the semantic similarity calculation method can be divided into two different algorithms: the distribution in the local ontology and the distribution in the scenario. The distribution algorithm in the scenario is designed for the existence of two ontology concepts in different local ontologies, but it can also be applied to the same local ontology. In order to make the experimental results comparable, two algorithms are used to calculate the case that different ontology concepts are in the same local ontology. For training sample 1 and training sample 2, mapping relations based on semantic similarity were established in domain ontology with decorative materials as the theme and domain ontology with electroplating technology as the theme, respectively. The experimental results of semantic similarity calculation are shown in Table 6 and Figure 10. According to the data in the table, when the threshold value is 0.5 , the precision of sample 1 and sample 2 reaches the maximum value, which is 0.88 and 0.6 , respectively; when the threshold value is 0.3 , the recall ratio of sample 1 and sample 2 reaches the maximum value, which is 0.92 and 0.66 , respectively. The threshold value $\theta$ and the sample size have a great influence on the final calculation results. Taking the appropriate value of $\theta$, increasing the coverage of samples, and expanding the number of samples, we can get better results. At the same time, the calculation of semantic correlation and similarity between ontologies can be completed in advance and stored in the database. Therefore, although the amount of calculation is large, it will not affect the speed of knowledge service calculation of designers in product design.

\section{Conclusions}

The core of modern enterprise competition is the ability of enterprise products and technology innovation. The response ability of enterprise products to the market is the key of enterprise management. The product is the main body of all enterprise activities. Whether the enterprise can be invincible in the future competition largely depends on whether the enterprise adopts advanced modern design means to develop market-oriented products faster and better. Usability testing should be organically combined with the design and development process of products, and the test results can guide the improvement of the product design scheme, which can effectively control the design cost, improve the product quality, and make the product have stronger market competitiveness.

This paper takes the product in the design process as the research object, through the relevant theoretical tools, and the concept design as the concept, and the implementation of the human-centered design principle, including the use of the computer intelligent microprocessor, in the product design process has not yet produced the product usability evaluation. Through the analysis and research of the main product design evaluation theory, a new idea and method of product design evaluation is realized.

Through effective integration with the product design CAD system, product database system, and remote access system with other department information of the enterprise, the integrated management of all information used and generated in the design process is realized. Evaluators can use the real-time and accurate intelligent microprocessor to evaluate the product. The entire evaluation process is not limited by the time and region and highly simulates the real use situation of the product so as to maximize the control of the uncertain factors of consumer demand and make the results more objective and accurate. 


\section{Data Availability}

The data that support the findings of this study are available from the corresponding authors upon reasonable request.

\section{Conflicts of Interest}

The authors declared no potential conflicts of interest with respect to the research, authorship, and/or publication of this article.

\section{Acknowledgments}

This work was supported by the Postdoctoral Science Foundation of China (2020M672101), the Postdoctoral Innovation Science Foundation of Shandong (202002046), and the International Cooperation Project of Qilu University, China (No. QLUTGJHZ2018022).

\section{References}

[1] P. Xia, "Haptics for product design and manufacturing simulation," IEEE Transactions on Haptics, vol. 9, no. 3, pp. 358-375, 2016.

[2] J. P. Pernot, B. Falcidieno, F. Giannini, and J. C. Léon, "Incorporating free-form features in aesthetic and engineering product design: state-of-the-art report," Computers in Industry, vol. 59, no. 6, pp. 626-637, 2016.

[3] G. Du, Y. Zhang, X. Liu, R. J. Jiao, Y. Xia, and Y. Li, “A review of leader-follower joint optimization problems and mathematical models for product design and development," The International Journal of Advanced Manufacturing Technology, vol. 103, no. 9-12, pp. 3405-3424, 2019.

[4] V. Tiwari, P. K. Jain, and P. Tandon, "Product design concept evaluation using rough sets and VIKOR method," Advanced Engineering Informatics, vol. 30, no. 1, pp. 16-25, 2016.

[5] T. Suh, J. Ford, Y. S. Ryu, and J. H. S. Kim, "Enhancing the simultaneous utilization of measure in product design for academic-practitioner collaboration," Journal of Product \& Brand Management, vol. 26, no. 3, pp. 312-326, 2017.

[6] D. Tang, R. Zhu, J. Tang, R. Xu, and R. He, "Product design knowledge management based on design structure matrix," Advanced Engineering Informatics, vol. 24, no. 2, pp. 159166, 2018.

[7] G. B. Loureiro, J. C. E. Ferreira, and P. H. Z. Messerschmidt, "Design structure network (DSN): a method to make explicit the product design specification process for mass customization," Research in Engineering Design, vol. 31, no. 2, pp. 197220, 2020.

[8] I. Belboula, C. L. Ackermann, J. P. Mathieu, and C. Cuny, "Consumers' responses to product design: using a semantic priming task to assess automatic understanding of product positioning," International Journal of Market Research, vol. 61, no. 2, pp. 140-156, 2019.

[9] D. Howard, "IoT product design considerations: security, functionality, interoperability," Appliance Design, vol. 66, no. 5, pp. 12-13, 2018.

[10] T. Maggio, "Senses to cultivate the collective consciousness: physical theatre, an experimental approach to product design education," Technoetic Arts, vol. 14, no. 3, pp. 275-281, 2016.
[11] C. Lu, H. Chai, M. Tian, X. Peng, and S. Jiang, "Product function combination design based on functional redundancy analysis," Concurrent Engineering, Research, and Applications, vol. 25, no. 3, pp. 229-244, 2017.

[12] C. Sassanelli, G. Pezzotta, F. Pirola et al., "Using design rules to guide the PSS design in an engineering platform based on the product service lifecycle management paradigm," International Journal of Product Lifecycle Management, vol. 11, no. 2, pp. 91-115, 2018.

[13] K. L. LaBat and S. L. Sokolowski, “A three-stage design process applied to an industry-university textile product design project," Clothing \& Textiles Research Journal, vol. 17, no. 1, pp. 11-20, 2016.

[14] L. P. Berg and J. M. Vance, "Industry use of virtual reality in product design and manufacturing: a survey," Virtual Reality, vol. 21, no. 1, pp. 1-17, 2017.

[15] F. Tao, L. N. Bi, Y. Zuo, and A. Y. C. Nee, "A hybrid group leader algorithm for green material selection with energy consideration in product design," CIRP Annals - Manufacturing Technology, vol. 65, no. 1, pp. 9-12, 2016.

[16] R. G. Askin and J. B. Goldberg, "Economic optimization in product design," Engineering Optimization, vol. 14, no. 2, pp. 139-152, 2016.

[17] S. Stegemann, R. L. Ternik, G. onder, M. A. Khan, and D. A. van Riet-Nales, "Defining patient centric pharmaceutical drug product design," The AAPS Journal, vol. 18, no. 5, pp. 1047$1055,2016$.

[18] K. M. Kim and K. P. Lee, "Collaborative product design processes of industrial design and engineering design in consumer product companies," Design Studies, vol. 46, no. 9, pp. 226260, 2016.

[19] K. Y. Lin, C. F. Chien, and R. Kerh, "UNISON framework of data-driven innovation for extracting user experience of product design of wearable devices," Computers \& Industrial Engineering, vol. 99, no. 9, pp. 487-502, 2016.

[20] Y. Xia, V. R. Singhal, and G. Peter Zhang, "Product design awards and the market value of the firm," Production \& Operations Management, vol. 25, no. 6, pp. 1038-1055, 2016.

[21] R. B. Malmiry, J. Pailhès, A. J. Qureshi, J. F. Antoine, and J. Y. Dantan, "Management of product design complexity due to epistemic uncertainty via energy flow modelling based on CPM," CIRP Annals-Manufacturing Technology, vol. 65, no. 1, pp. 169-172, 2016.

[22] A. Wong, M. Sherris, and R. Stevens, "Natural hedging strategies for life insurers: impact of product design and risk measure," Journal of Risk \& Insurance, vol. 84, no. 1, pp. 153$175,2017$.

[23] M. F. Hassan, M. Z. M. Saman, S. Sharif, and B. Omar, "Sustainability evaluation of alternative part configurations in product design: weighted decision matrix and artificial neural network approach," Clean Technologies \& Environmental Policy, vol. 18, no. 1, pp. 63-79, 2016.

[24] M. Kumar and C. H. Noble, "Beyond form and function: why do consumers value product design?," Journal of Business Research, vol. 69, no. 2, pp. 613-620, 2016.

[25] R. P. Jindal, K. R. Sarangee, R. Echambadi, and S. Lee, "Designed to succeed: dimensions of product design and their impact on market share," Journal of Marketing, vol. 80, no. 4, pp. 72-89, 2016.

[26] S. Nazari-Shirkouhi and A. Keramati, "Modeling customer satisfaction with new product design using a flexible fuzzy 
regression-data envelopment analysis algorithm," Applied Mathematical Modelling, vol. 50, no. 10, pp. 755-771, 2017.

[27] H. Zhang, X. Han, R. Li, S. Qin, G. Ding, and K. Yan, “A new conceptual design method to support rapid and effective mapping from product design specification to concept design," International Journal of Advanced Manufacturing Technology, vol. 87, no. 5-8, pp. 2375-2389, 2016.

[28] J. de Aguiar, L. de Oliveira, J. O. da Silva, D. Bond, R. K. Scalice, and D. Becker, "A design tool to diagnose product recyclability during product design phase," Journal of Cleaner Production, vol. 141, no. 1, pp. 219-229, 2017.

[29] J. Liu, Z. Cheng, and Y. Ma, "Product design-optimization integration via associative optimization feature modeling," Advanced Engineering Informatics, vol. 30, no. 4, pp. 713$727,2016$. 